\title{
Phenotype in Candida albicans of a disruption of the BGL2 gene encoding a 1,3 - $\beta$-glucosyltransferase
}

\author{
Aparna V. Sarthy, Thomas McGonigal, Michael Coen, David J. Frost, \\ Jonathan A. Meulbroek and Robert C. Goldman
}

Anti-infective Research Division, D47M/AP9A, 100 Abbott Park Road, Abbott Laboratories, Abbott Park, IL 60064-3500, USA

\author{
Author for correspondence: Robert C. Goldman. Tel: +1847937 4477. Fax: +18479386603. \\ e-mail: robert.goldman@abbott.com
}

\begin{abstract}
The BGL2 gene encodes a unique 1,3- $\beta$-glucosyltransferase (Bgl2p) present in the cell wall of Candida albicans and other fungi. Although believed to be involved in cell wall assembly, disruption of the gene in Saccharomyces cerevisiae showed no apparent phenotype. We performed sequential disruptions of the BGL2 loci in a homozygous ura3 clinical isolate of $C$. albicans using the URA3 blaster method, in order to investigate the role of Bgl2p in this dimorphic, pathogenic fungus. Strain CACW-1 contained disruptions of both homologues of the BGL2 gene and lacked Bgl2p, as assessed by protein extraction, SDS-PAGE and Western blot analysis, and enzyme assay; however, residual non-Bgl2p transferase activity was detected. CACW-1 was attenuated in virulence for mice when compared to an isogenic parent strain, and fewer organisms were recovered from the kidneys of infected animals. Additional phenotypic changes included: (1) a dramatic increase in the sensitivity to the chitin synthesis inhibitor nikkomycin $\mathrm{Z}$ when CACW-1 cells were incubated at 37 or $42{ }^{\circ} \mathrm{C}$; (2) an $8.7 \pm 1.6 \%$ slower growth rate at $37^{\circ} \mathrm{C}$ for $\mathrm{CACW}-1$ when compared to its isogenic parent; and (3) aggregation of CACW-1 cells during stationary phase and/or incubation of stationary phase cells in phosphate buffer. Characterization of SDS-extracted cell walls did not reveal any significant differences in the levels of 1,3- $\beta$ - or $1,6-\beta$-glucan. These data reveal that loss of Bgl2p does have a phenotype in C. albicans, and indicate that (1) loss of Bgl2p function renders cells more dependent on chitin for wall integrity, and attenuates virulence (probably due to subtle changes in wall structure), and (2) that additional 1,3- $\beta$-glucosyltransferases are present in the C. albicans BGL2 disruptant.
\end{abstract}

Keywords: Candida albicans, BGL2, transglycosylation

\section{INTRODUCTION}

The biochemistry and structure of the fungal cell wall represent some of the few and clear differences between fungal and mammalian cells. The cell wall provides many functions, including maintenance of cell shape, protection from damage by extracellular agents, protection from osmotic forces, and expression of virulence properties facilitating interaction of the pathogen with the host (Reiss et al., 1992; Shepherd, 1987; Shepherd et al., 1985). The cell wall is therefore an attractive target for antifungal drug development, and specific lipopeptide (echinocandin class), glycolipid (papulacandin class) and peptidyl-nucleotide (polyoxin class) com- pounds are either in preclinical or clinical development as antifungal agents which affect cell wall synthesis. In addition, a study has shown that reduction of the chitin content of the cell wall of Candida albicans via disruption of the CSD2/CAL1/DIT101/KTI2 gene (the C. albicans homologue of the Saccharomyces cerevisiae $\mathrm{CHS} 3$ gene) resulted in attenuation of virulence of this pathogen (Bulawa et al., 1995), demonstrating that nonlytic alterations in fungal cell wall synthesis can decrease fungal virulence in vivo. The magnitude of this effect may be in question based on a separate study (Mio et al., 1996).

A large number of mannoproteins as well as an extensive 
glucan and chitin network make up the architecture of the cell wall of $S$. cerevisiae and other fungi (Shepherd, 1987; Shepherd et al., 1985). Recent data have confirmed the existence of covalent linkages between various structural components of the fungal cell wall, including chitin and glucan (Elorza et al., 1989; Sietsma \& Wessels, 1981; Surarit et al., 1988; Kollar et al., 1995). The action of wall-associated glycosyltransferases is the most likely mechanism for formation of such covalent linkages. A novel $35 \mathrm{kDa}$ glucosyltransferase encoded by the BGL2 gene, first described in C. albicans (Hartland et al., 1991), catalyses the following transferase reaction with $1,3-\beta$-glucan:

$\mathrm{E}+\mathrm{G}_{n} \rightarrow \mathrm{E}: \mathrm{G}_{n-2}+\mathrm{G}_{2}$

$\mathrm{E}: \mathrm{G}_{n-2}+\mathrm{G}_{\mathrm{y}} \rightarrow \mathrm{E}+\mathrm{G}_{n+y-2}$

where $\mathrm{E}$ is the enzyme, $\mathrm{G}_{n}$ is the donor $(n \geqslant 5), \mathrm{E}: \mathrm{G}_{n-2}$ is the enzyme: glucosyl intermediate, $G_{2}$ is the released disaccharide laminaribiose, $\mathrm{G}_{y}$ is the acceptor glucan $(y \geqslant 4)$ and $\mathrm{G}_{n+y-2}$ is the transferase product which contains a 1,6- $\beta$-linkage at the transfer site (Hartland $e t$ al., 1991; Goldman et al., 1995). The BGL2-encoded enzyme is present in S. cerevisiae (Goldman et al., 1995; Klebl \& Tanner, 1989; Mrsa et al., 1993) and the pathogenic fungi C. albicans (Hartland et al., 1991) and Aspergillus fumigatus ( $\mathrm{R}$. Hartland, personal communication). The transferase reaction catalysed by the Bgl2p enzyme is not essential for growth in S. cerevisiae (Klebl $\&$ Tanner, 1989). However, we previously reported that a Bgl2p-like enzyme probably was functional in $S$. cerevisiae (Coen et al., 1994), as one of the products, laminaribiose $\left(G_{2}\right)$, was released from cell wall glucan during growth. The $B G L 2$ gene product was originally described as an exoglucanase (Klebl \& Tanner, 1989), then as an endoglucanase (Mrsa et al., 1993), but is now known to have active transglycosylase function (Hartland et al., 1991; Goldman et al., 1995). Structural analysis of Bgl2p reveals that it is uniquely specialized for transferase function (C. Hutchins \& R. Goldman, unpublished).

We initiated a study in $C$. albicans to determine the effects of loss of the Bgl2p enzyme activity on growth, wall structure/function and/or pathogenicity. Strains deficient in the Bgl2p enzyme can also be used to characterize other glucosyltransferase activities that may be essential for cell wall assembly. The present study describes the disruption of both copies of the $B G L 2$ gene in a clinical isolate of C. albicans. The strain was further evaluated for the presence of glucosyltransferase activity and virulence using a mouse model system. Low levels of non-Bgl2p glucosyltransferase activity were detectable in this strain. The strain also showed a slight attenuation of virulence as compared to the BGL2 parent, and fewer C. albicans were recovered from the kidneys of infected mice.

\section{METHODS}

Yeast strains, plasmids and media. The $C$. albicans strains used are listed in Table 1. Strain CAI-4 was used to disrupt the $B G L 2$ gene homologues in the construction of CACW- 0 and
CACW-1. The bisG-URA3-bisG and C. albicans BGL2 sequences are contained in pMB7 (Fonzi \& Irwin, 1993) and pDS14 (provided by P. A. Sullivan, Massey University, New Zealand), respectively, and were used to construct strains containing disruptions in the BGL2 gene. Yeast strains were maintained on YPD medium (Sherman et al., 1982) supplemented with $25 \mu \mathrm{g}$ uridine $\mathrm{ml}^{-1}$. Synthetic depleted (SD) medium contained $0.67 \%$ Yeast Nitrogen Base (Difco) and $2 \%(\mathrm{w} / \mathrm{v})$ glucose (Sherman et al., 1982). Uridine auxotrophs were selected by the 5 -fluoroorotic acid method as described by Boeke et al. (1984) and maintained on medium supplemented with uridine. SD medium was supplemented with $25 \mu \mathrm{g}$ uridine $\mathrm{ml}^{-1}$ when required.

Plasmid construction, and transformation. A 930 bp PCR fragment was amplified from pDS14 such that the BGL2 coding sequence was flanked by a unique SalI site at the $5^{\prime}$ end and unique BglII and BamHI sites at the $3^{\prime}$ end. PCR amplification was performed using the Perkin Elmer Cetus thermal cycler and GeneAmp kit with the primers $5^{\prime}$ TGTGTAGTCGACTACTCTCGCAACTGTTCT $3^{\prime}$ and $5^{\prime}$ AGAGTGGATCCAGATCTAGACAATCAAAAAACAC $3^{\prime}$. Thirty cycles of $94^{\circ} \mathrm{C} / 30 \mathrm{~s}$ melting, $55^{\circ} \mathrm{C} / 1 \mathrm{~min}$ annealing and $72{ }^{\circ} \mathrm{C} / 1 \mathrm{~min}$ extension steps were used for the amplification. The PCR product was digested with BamHI and SalI and cloned into the BamHI and Sall sites of pBluescript KS (Stratagene) to create pBSCaBGL2. Plasmid pMB7 (Fonzi \& Irwin, 1993) was digested with Sall and Bglll to release a $3.9 \mathrm{~kb}$ fragment containing the bisG-URA3-hisG cassette. This fragment was blunt-end ligated into the flush-ended EcoRI site in the $B G L 2$ gene of pBSCaBGL2 to generate pCBHUH1. A $5 \mathrm{~kb}$ $B g l$ II-SalI fragment containing the his $G-U R A 3-h i s G$ cassette inserted into the $B G L 2$ gene was isolated from pCBHUH1 and transformed into $C$. albicans as described by Burgers \& Percival (1987). Uridine prototrophs were selected on SD medium lacking uridine.

Southern blot analysis. Yeast genomic DNA was extracted as described by Hoffman \& Winston (1987). Approximately $5 \mu \mathrm{g}$ DNA was digested with EcoRI and electrophoresed on an agarose gel which was then transferred onto Hybond- $N$ paper (Amersham). Southern blot analysis was done as described by Maniatis et al. (1982) using a ${ }^{32} \mathrm{P}$-labelled fragment containing the Candida BGL2 gene as probe.

Growth rate measurements. Strains were grown overnight at $37{ }^{\circ} \mathrm{C}$ in SD medium with limiting glucose $(0.1 \%)$ and transferred to SD medium containing $0.5 \%$ glucose to a final $\mathrm{OD}_{420}$ of 0.05 (measured using a Bausch \& Lomb Spectronic 1001 spectrophotometer). Cells were grown at $37^{\circ} \mathrm{C}$ with shaking, and mildly sonicated for $10 \mathrm{~s}$ in a Bransonic model 220 sonicator bath to disrupt clumps prior to reading the optical density value. Cultures were diluted before reading to obtain optical density values below 1.0 when required, in order to avoid non-linear readings. The generation time was determined in triplicate, and converted to $k$ (the instantaneous growth rate constant) by the formula $g=\ln 2 / k$, where $g$ is expressed in hours.

Aggregation measurements. The tendency towards aggregation was monitored in both exponential- and stationaryphase cells grown in SD medium plus $0.5 \%$ glucose. Exponential-phase cells were harvested at an optical density value of 2.0-3.0, while stationary-phase cells were from cultures grown for $16 \mathrm{~h}$. Cells were washed once with PBS $(0.137 \mathrm{M} \mathrm{NaCl}$; $2.7 \mathrm{mM} \mathrm{KCl} ; 0.10 \mathrm{M}$ sodium phosphate), once with $0.066 \mathrm{M}$ sodium/potassium phosphate buffer ( $\mathrm{pH} 7.5$ ) and resuspended in $0.066 \mathrm{M}$ phosphate buffer to an $\mathrm{OD}_{800}$ value of about 1.0 . Cells were incubated with shaking at 200 r.p.m. in a New 
Table 1. C. albicans strains

\begin{tabular}{|c|c|c|}
\hline Strain & Genotype & Source \\
\hline CAF2 & $\Delta u r a 3:: i m m 434 / U R A 3$ & $\begin{array}{l}\text { W. A. Fonzi } \\
\text { (Georgetown } \\
\text { University } \\
\text { Medical Center, } \\
\text { Washington, } \\
\text { DC, USA) }\end{array}$ \\
\hline $\mathrm{CAI}-4$ & 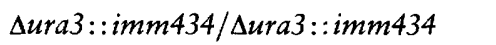 & As above \\
\hline CACW-0 & 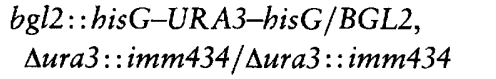 & This study \\
\hline CACW-1 & $\begin{array}{c}\text { bgl2::bisG/bgl2::bisG-URA3-bisG, } \\
\text { Aura3::imm } 434 / \text { Aura3::imm } 434\end{array}$ & This study \\
\hline
\end{tabular}

Brunswick Aquatherm water-bath shaker at $37^{\circ} \mathrm{C}$, and the optical density value was determined over time. Alternatively, cells were examined microscopically and the frequency distribution of aggregates was determined by triplicate counting of 100-150 aggregates. Aggregates of size two or more may represent mother-daughter associations that had not separated, or more distantly related cells which had aggregated together when cells were examined directly from culture.

Zymolyase sensitivity. The sensitivity towards lysis by Zymolyase 100T (Seikagaku America) was determined for both exponential- and stationary-phase cells prepared as given above for aggregation measurements. Cells suspended in $0.02 \mathrm{M}$ phosphate buffer with varying amounts of Zymolyase $100 \mathrm{~T}$ were incubated at $37^{\circ} \mathrm{C}$ with shaking, and the optical density value was determined with time. Data were plotted and the rate of lysis was determined from the linear portion of the curve (time vs optical density value).

Germ tube formation upon glucose starvation. Cells were grown overnight at $37^{\circ} \mathrm{C}$ in SD medium plus $0 \cdot 1 \%$ glucose. Coded samples were analysed in a cell counting chamber for total cell number and percentage germ tubes. Microscopy fields ( 10 per sample) were counted, and the standard deviation was determined.

MIC profiles. The MIC values for various drugs were determined by micro broth dilution in 96-well microtitre trays, using cells grown in SD medium plus $0.5 \%$ glucose. Cells were inoculated to about $2 \times 10^{5}$ cells $\mathrm{ml}^{-1}$ in $100 \mu \mathrm{l}$ media containing twofold serial dilutions of drugs. Plates were incubated at the indicated temperatures and monitored for growth on days 1, 2 and 4. MIC profiles were determined three to five times, depending on the drug, with similar results, and representative data are reported.

Bgl2p extraction and analysis. Glucosyltransferase activity was extracted from walls as previously described (Goldman et al., 1995). Briefly, $16 \mathrm{~g}$ cell paste was thawed in $5 \mathrm{ml} 25 \mathrm{mM}$ Tris $/ \mathrm{HCl}(\mathrm{pH} \mathrm{7.5)}$ and mixed with $45 \mathrm{ml}$ acid-washed $0.5 \mathrm{~mm}$ glass beads in a Braun $70 \mathrm{ml}$ glass cylinder. Cells were maintained at $4{ }^{\circ} \mathrm{C}$ with $\mathrm{CO}_{2}$ cooling and broken using a Braun type 853030 cell disrupter. The cell wall pellet was washed once with cold distilled $\mathrm{H}_{2} \mathrm{O}$ by centrifugation $(10000 \mathrm{~g}$ for $10 \mathrm{~min}$ ) and the pellet wet weight was recorded. The pellet was resuspended in cold distilled $\mathrm{H}_{2} \mathrm{O}(1.8 \times$ wet wt) and transferred to a glass Corex tube. The pellet was extracted with butanol $(1.2 \times$ wet wt $)$ at $4{ }^{\circ} \mathrm{C}$ for $15 \mathrm{~min}$ with gentle rocking, then centrifuged at $10000 \mathrm{~g}$ for $5 \mathrm{~min}$ at $4^{\circ} \mathrm{C}$ and the supernatant was discarded. The extraction and centrifugation steps were repeated two more times. The cell wall pellet was washed once with cold distilled $\mathrm{H}_{2} \mathrm{O}$ by centrifugation, and the pellet wet weight was recorded. The pellet was resuspended in $5 \mathrm{mM}$ Tris $/ \mathrm{HCl}(\mathrm{pH} \mathrm{7.5)}(2.0 \times$ wet wt) and heated at $70{ }^{\circ} \mathrm{C}$ for $10 \mathrm{~min}$. The sample was cooled by addition of $1 \times$ volume of $5 \mathrm{mM}$ Tris $/ \mathrm{HCl}(\mathrm{pH} 7 \cdot 5)$ and centrifuged at $30000 \mathrm{~g}$ for $30 \mathrm{~min}$ at $4{ }^{\circ} \mathrm{C}$. The supernatant was concentrated to approximately $500 \mu \mathrm{l}$ and assayed for protein concentration and glucosyltransferase activity. Protein extracts were separated by SDS-PAGE (4-20\%, w/v, acrylamide) and analysed by Western blotting using antiserum raised against $\mathrm{Bgl} 2 \mathrm{p}$ (1:5000 dilution) isolated from $S$. cerevisiae, and goat anti-rabbit IgG (peroxidase-conjugated; $1: 5000$ dilution).

Glucosyltransferase assay. Reagents were prepared and reactions were conducted as previously described (Goldman et al., 1995). Briefly, this included preparation of labelled glucan using C. albicans microsomes in a final volume of $2 \mathrm{ml} 2 \mathrm{mM}$ UDP- $\left[{ }^{3} \mathrm{H}\right]$ Glc [Amersham TRK.385; $12.3 \mathrm{Ci}\left(4.55 \times 10^{11} \mathrm{~Bq}\right)$ $\mathrm{mmol}^{-1}$; final specific activity of $62-124 \mathrm{mCi}\left(3.7 \times 10^{7} \mathrm{~Bq}\right)$ $\mathrm{mmol}^{-1}$ ], $1 \mathrm{mM}$ EDTA, $8 \%$ (v/v) glycerol, $20 \mu \mathrm{M}$ GTP $\gamma$, $0.5 \%$ Brij-35, $80 \mathrm{mM}$ Tris $/ \mathrm{HCl}(\mathrm{pH} 7.75$ ) and microsomes (2 mg protein). Glucan was precipitated with 2 vols cold $95 \%$ ethanol, and the dried glucan was digested with laminaripentaohydrolase prepared from Zymolyase $100 \mathrm{~T}$. The soluble glucan oligosaccharides were purified on Sephadex G50 and then by HPLC as described by Goldman et al. (1995), and stored at $-20^{\circ} \mathrm{C}$ in $\mathrm{H}_{2} \mathrm{O}$ containing $1 \%$ ethanol. Laminarioligosaccharides and glucosyltransferase reaction products were separated on a Dynamax-60A $8 \mu \mathrm{m} \mathrm{NH} \mathrm{NH}_{2}$ column, $4.6 \mathrm{~mm}$ internal diameter $\times 25 \mathrm{~cm}$ (Rainin Instrument), using $60 \%$ $(\mathrm{v} / \mathrm{v})$ acetonitrile as the mobile phase and a flow rate of $1 \mathrm{ml}$ $\mathrm{min}^{-1}$. Radioactivity was monitored with a Radiomatics flow detector (United Packard).

Characterization of cell walls. Cells from $20 \mathrm{ml}$ culture were mixed with an equal volume of acid-washed $0.5 \mathrm{~mm}$ glass beads and broken by vortexing four times for $1 \mathrm{~min}$. Walls were collected by centrifugation, resuspended in $3 \mathrm{ml} 2 \%$ $(\mathrm{w} / \mathrm{v}) \mathrm{SDS}$ in $10 \mathrm{mM}$ Tris $/ \mathrm{HCl}\left(\mathrm{pH} \mathrm{7.5)}\right.$ and heated to $100^{\circ} \mathrm{C}$ for $5 \mathrm{~min}$. Walls were centrifuged as above and the pellets were washed twice with $5 \mathrm{ml} \mathrm{H}_{2} \mathrm{O}$ to remove the SDS. Walls $(0.5 \mathrm{ml} ; 2 \mathrm{mg}$ dry wt in $20 \mathrm{mM}$ ammonium acetate, $\mathrm{pH} 5.6)$ were digested with 100 units Zymolyase $100 \mathrm{~T}$ in $0.02 \%$ 
sodium azide overnight at $37^{\circ} \mathrm{C}$ with rotation. Following digestion, the reaction mixture was heated to $60^{\circ} \mathrm{C}$ for $5 \mathrm{~min}$ to inactivate the Zymolyase enzymes. Particulate matter was removed by centrifugation and the supernatants were frozen at $-20^{\circ} \mathrm{C}$ for subsequent total hexose determination using the phenol-sulfuric acid method (Dubois et al., 1956). Zymolyase-soluble material was fractionated on Sephadex G50 columns $(10 \mathrm{ml}$ bed volume in $20 \mathrm{mM}$ ammonium acetate, $\mathrm{pH}$ $5.6)$, collecting $0.75 \mathrm{ml}$ fractions. The material from peak 1 (void volume) was pooled, lyophilized and resuspended in $300 \mu \mathrm{l} 25 \mathrm{mM}$ sodium acetate (pH 4.2).

Each peak 1 sample was digested with 0.04 units $(1$ unit $=$ $1 \mu \mathrm{mol}$ reducing sugar released $\mathrm{min}^{-1}$ ) of endo-1,6- $\beta$-exoglucanase for $1 \mathrm{~h}$ at $50^{\circ} \mathrm{C}$, followed by an additional 0.04 units for another $1 \mathrm{~h}$ digestion. Each sample was centrifuged through a Microcon 3 membrane (Filtron; $3000 \mathrm{Da}$ cut-off) to near-dryness and the membrane was washed three times with $100 \mu \mathrm{l} 25 \mathrm{mM}$ sodium acetate (pH 4.2). The filtrates were combined and assayed for hexose content. In addition, the retentate was resuspended in $1 \mathrm{ml}$ buffer and assayed for hexose content. The amount of hexose passing through the membrane as filtrate was used to quantify the amount of material in peak 1 which was susceptible to $1,6-\beta$-exoglucanase digestion.

Virulence studies. Cells were grown overnight in Sabouraud broth at $37^{\circ} \mathrm{C}$ with shaking. Cultures were diluted in phosphate buffer and groups of ten mice (CF-1) were inoculated with $0.2 \mathrm{ml}$ of each dilution via a lateral tail vein. Mice were monitored for $28 \mathrm{~d}$. Colonization and survival in kidney tissue were monitored by inoculating mice as above. At days 1 and 4 post-inoculation, kidney homogenates from 10 mice from each group were plated on Sabouraud Dextrose Agar (Difco) and colony counts were determined after $24 \mathrm{~h}$ incubation at $37^{\circ} \mathrm{C}$.

Reagents. Cilofungin was obtained from Eli Lilly \& Co.; fusacandin A was isolated at Abbott Laboratories; Calcofluor white and miconazole were purchased from Sigma. Nikkomycin $Z$, tunicamycin and staurosporine were purchased from CalBiochem. Amphotericin B was purchased from GibcoBRL. Zymolyase 100T was from Seikagaku America. Antibody to the $S$. cerevisiae Bgl2p, and purified endo-1,6- $\beta$ glucanase from Eupenicillium brefeldianum were kindly provided by Dr P.A. Sullivan, Massey University, New Zealand.

\section{RESULTS AND DISCUSSION}

\section{Sequential disruption of the BGL2 gene in C. albicans CAI-4}

A homozygous ura 3 mutant clinical isolate, C. albicans CAI-4, was used to sequentially disrupt the BGL2 loci using the method described by Fonzi \& Irwin (1993). A $3.9 \mathrm{~kb}$ DNA fragment containing the Candida URA3 gene flanked by repeats of the Salmonella bisG gene was first inserted into the EcoRI site located in the coding region of the C. albicans $B G L 2$ gene. The restriction map of the wild-type $B G L 2$ gene containing the insertion of the hisG-URA3-bisG cassette at the EcoRI site is shown in Fig. 1. The parental strain CAI-4 was then transformed with the BglII-SalI fragment containing the his $G-U R A 3-$ his $G$ cassette flanked by $B G L 2$ sequences. Southern analysis of three $\mathrm{URA}^{+}$transformants indi-
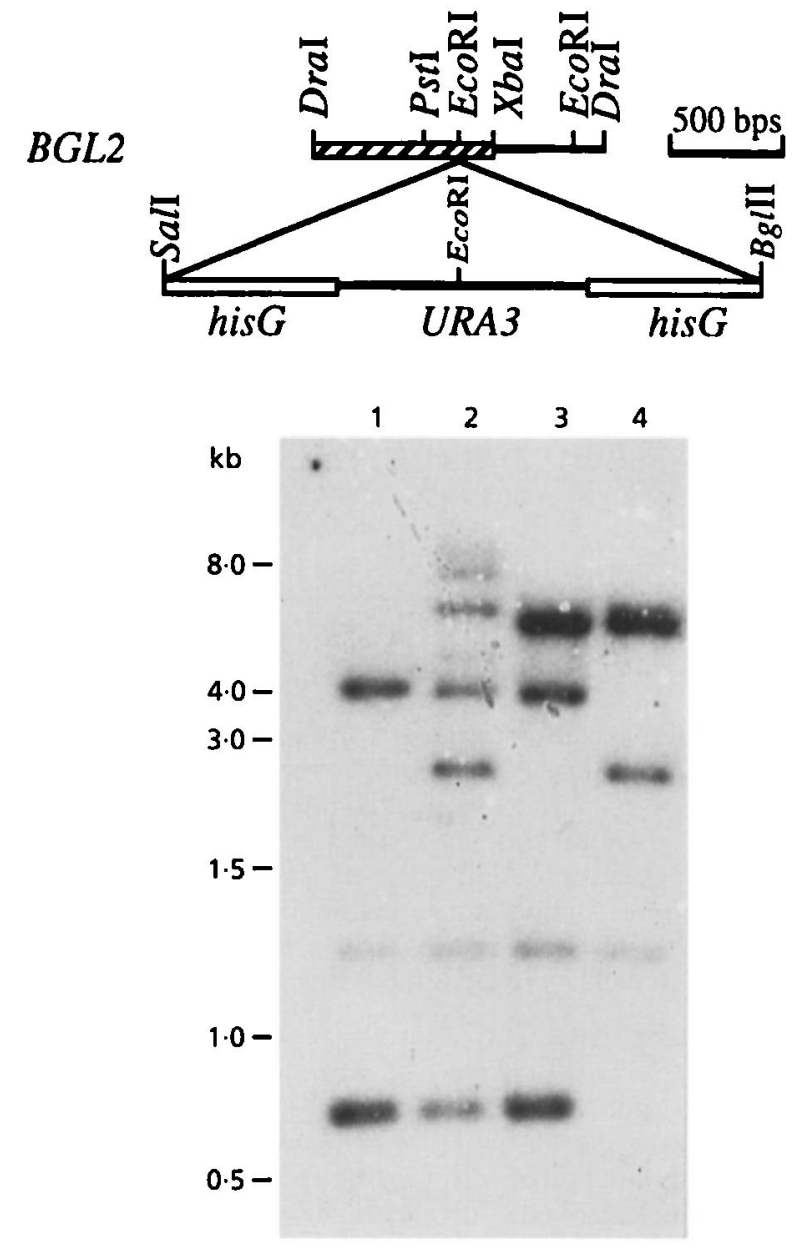

Fig. 1. Southern blot analysis of C. albicans BGL2 disruptants. The coding sequence for Bgl2p (hatched) is contained on a Dral-Xbal fragment (upper panel). Insertion of the hisG-URA3-hisG cassette is at the ECoRI site. Lower panel: Southern blot analysis of genomic DNA from CAl-4 and its transplacements. Lanes 1-4 contain DNA digested with EcoRI from CAl-4, heterozygote CACW- 0 containing the primary bg/2 disruption, the uracil-requiring recombinant of CACW-O and the $b g / 2$ double disruptant CACW-1, respectively. The blot was probed with a $0.9 \mathrm{~kb}$ PCR fragment (hatched) labelled with ${ }^{32 \mathrm{p}}$ (MegaPrime; Amersham).

cated that one transformant, CACW- 0 , contained a disruption of one of the two $B G L 2$ genes by insertion of the hisG-URA3-bisG DNA construct.

ura3 mutant derivatives were obtained from CACW-0 by first growing in non-selective (YEPD) medium to saturation and then plating on SD medium containing 5fluoroorotic acid plus uridine to select for uridine auxotrophs. Southern analysis of six uridine auxotrophs showed that all contained $b g l 2:$ : his $G$, which should have arisen by intragenic recombination between the two copies of the bis $G$ sequences. A homozygous disruption at the $B G L 2$ locus was obtained by transformation with the same BglII-Sall fragment containing the his $G-U R A 3-b i s G$ sequences inserted into the BGL2 


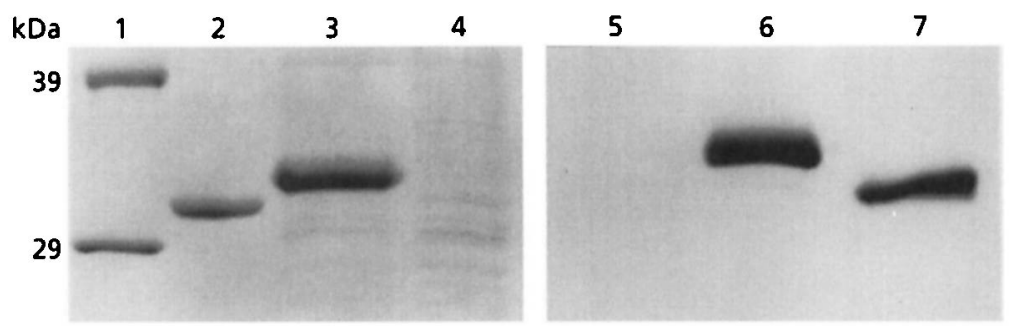

Fig. 2. SDS-PAGE analysis of protein extracted from cell walls. Extracts of wall proteins were prepared from CAl-4 and CACW-1 and protein $(50 \mu \mathrm{g})$ was electrophoresed on $12.5 \%$ acrylamide gels and either stained for protein (lanes 1-4) or Western blotted and probed with antibody to $S$. cerevisiae Bgl2p (lanes 5-7). Lanes: 1, molecular mass markers; 2 and $7,1 \mu \mathrm{g}$ and $100 \mathrm{ng}$ purified $S$. cerevisiae Bgl2p, respectively; 3 and 6 , extract from CAI-4 (parent strain); 4 and 5 , extract from CACW1 (BGL2 double disruptant). Note that the $C$. albicans Bgl2p migrates slightly more slowly compared to Bgl2p from $\mathrm{S}$. cerevisiae.

Table 2. Analysis of 1,3- $\beta$-glucosyltransferase activity in C. albicans

Radiolabelled $\mathrm{G}_{5}$ (laminaripentaose) was incubated with wall extract protein for $3 \mathrm{~h}$, and products were separated by HPLC analysis. $G_{8}$ and $G_{11}$ are the expected Bgl2p reaction products arising from $G_{5}$ by the enzyme equation $2 G_{n} \rightarrow G_{2 n-2}+G_{2}$ followed by the reaction $G_{n}+G_{2 n-2} \rightarrow G_{3 n-4}+G_{2}$, where $n=5 . \mathrm{G}_{x}$ represents transferase products of unknown structure.

\begin{tabular}{|c|c|c|c|c|c|c|}
\hline \multirow{2}{*}{$\begin{array}{l}\text { HPLC } \\
\text { run }\end{array}$} & \multicolumn{3}{|c|}{ CAI-4 (parent) } & \multicolumn{3}{|c|}{ CACW-1 (BGL2 disruptant) } \\
\hline & $\mathrm{G}_{8}$ c.p.m. & $\mathrm{G}_{11}$ c.p.m. ${ }^{*}$ & $\mathrm{G}_{x}$ c.p.m. & $\mathrm{G}_{8}$ c.p.m. & $\mathrm{G}_{11}$ c.p.m. & $\mathrm{G}_{x}$ c.p.m. \\
\hline Run & 50 & 25144 & 75785 & 0 & 0 & 63395 \\
\hline Run & 47645 & 25 & 74725 & 0 & 0 & 129588 \\
\hline Mean & $49185(3.98)$ & $25125(1.48)$ & $75255(4 \cdot 8) \dagger$ & $(<0 \cdot 2) \neq$ & $(<0 \cdot 1) \neq$ & $963661(6 \cdot 2) \dagger$ \\
\hline
\end{tabular}

*Values in parentheses are nmol product produced.

† Value in parentheses is the percentage of total labelled $G_{5}$ converted to product.

$\ddagger$ No $G_{8}$ or $G_{11}$ product was detected within the nmol limits given.

gene. Only two out of $28 \mathrm{URA}^{+}$transformants contained insertion of the cassette at the second BGL2 locus as determined by Southern analysis (Fig. 1). One of the transformants, CACW-1, was used for further studies.

\section{Biochemical characterization of CACW-1}

Bgl2p protein was missing from walls of CACW-1, as assessed by SDS-PAGE and Western blot analysis (Fig. 2 ). The Bgl2p from $S$. cerevisiae runs slightly faster on SDS-PAGE compared to the homologous protein from C. albicans CAI-4 (Fig. 2, lanes 2 and 3, respectively). No comparable band was found in the extract prepared from CACW-1. Antibody raised against Bgl2p from $S$. cerevisiae cross-reacted with Bgl $2 \mathrm{p}$ from C. albicans (Fig. 2, lanes 6 and 7). No Bgl2p cross-reacting material was detected in the extract from CACW-1 (Fig. 2, lane 5). Consistent with these findings, $G_{8}$ and $G_{11}$ transferase products were not detected when $G_{5}$ (laminaripentaose) was incubated with cell wall extracts from $C$. albicans CACW-1 (Table 2). As expected, $\mathrm{G}_{8}$ and $\mathrm{G}_{11}$ transferase products were detected when extracts of parental strain CAI-4 were incubated with $G_{5}$. However, transferase products of unknown structure, which did not comigrate with $G_{8}$ or $G_{11}$, were detected as reaction products using extracts of both CAI-4 and CACW-1.

The growth rate of CACW-1 $(g=1.23 \pm 0.039 \mathrm{~h}, k=$ $0.563 \pm 0.018$ ) was slightly slower than the growth rate of CAF2 ( $g=1.13 \pm 0.019 \mathrm{~h}, k=0.613 \pm 0.010)$ when grown in SD medium plus $0.5 \%$ glucose. We noted that the $\mathrm{OD}_{420}$ value of overnight cultures of CACW-1 was always lower by $30-40 \%$ compared to CAF2. Although there was a slight tendency for CACW-1 to aggregate during growth at $37^{\circ} \mathrm{C}$, extensive aggregation of stationary-phase cells occurred (Fig. 3). Aggregation was observed microscopically, and followed by monitoring the $\mathrm{OD}_{800}$ value of cells incubated in phosphate buffer $(\mathrm{pH} 7 \cdot 5)$. Vigorous mixing or mild sonication disrupted aggregates, i.e. aggregation as observed microscopically was reduced, and the $\mathrm{OD}_{800}$ reading increased. However, no significant difference in cell aggregation was observed when CAF2 and CACW-1 were grown to stationary phase in Sabouraud Dextrose Broth (Fig. 4), nor were any observable hyphae formed by either strain under these conditions. There was no difference in the number of yeast $\left(2.96 \pm 0.13 \times 10^{7}\right.$ yeast $\left.\mathrm{ml}^{-1}\right)$ or the number of hyphal forms $(2 \cdot 14 \pm 0.93 \times$ $10^{6} \mathrm{ml}^{-1}$ ) produced when two individual colonies of 


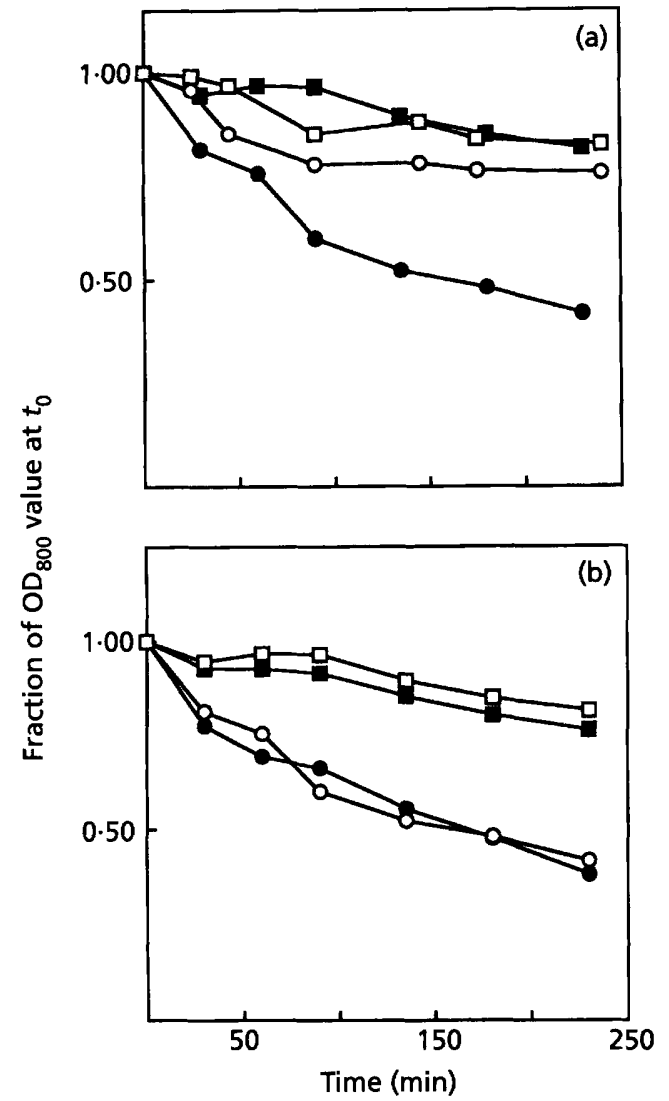

Fig. 3. Aggregation of CACW-1 cells. Cells grown in SD medium plus $0.5 \%$ glucose were washed and resuspended in phosphate buffer $(\mathrm{pH} 7.5)$ at $37^{\circ} \mathrm{C}$. Aggregation of CAF2 and CACW-1 exponential- and stationary-phase cells was measured over time by monitoring the $\mathrm{OD}_{800}$ value. (a) Exponential- and stationaryphase cells of both strains were compared. $\square$, CAF2 exponential-phase cells; $0, C A C W-1$ exponential-phase cells; 口, CAF2 stationary-phase cells; 0, CACW-1 stationary-phase cells. (b) Two independent colonies of CAF2 $(\square, \square)$ and CACW$1(0,0)$ were grown to stationary phase and aggregation was examined. Stationary-phase cells of $C A C W-1$ were prone to aggregation.

each strain were compared by growth in glucose-limited $\mathrm{SD}(0 \cdot 1 \%$ glucose $)$.

In addition, preliminary analysis of the $1,3-\beta$ - and $1,6-\beta$ glucan and mannan fractions did not reveal any significant differences (Table 3 and Fig. 5). Equivalent amounts of hexose were released by Zymolyase $100 \mathrm{~T}$ treatment of walls isolated from exponential- or stationary-phase cells of CAF2 and CACW-1 (Table 3). Zymolyase-released material separated into two fractions by size exclusion chromatography on Sephadex G50 (Fig. 5). Peak 1 (void volume) material contained approximately equal amounts of $1,6-\beta$-glucan (glucose) and mannan (mannose) as assessed by gas chromatographic analysis of peracetylated alditol acetates, and methylation analysis (data not shown). Peak 2 contained 1,3- $\beta$-oligosaccharides as assessed by TLC, HPLC, methylation analysis and NMR (data not shown). Between 60 and $80 \%$ of the hexose in peak

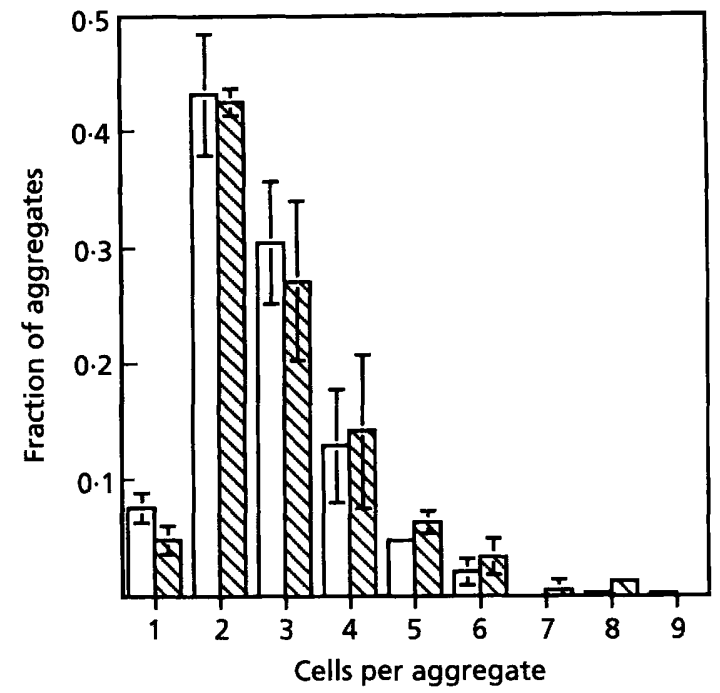

Fig. 4. Aggregation profile of stationary phase cells in Sabouraud Dextrose Broth. Cells were grown overnight to stationary phase at $37^{\circ} \mathrm{C}$, and analysed microscopically using a slide counting chamber. Triplicate preparations were analysed for aggregation state by counting 100-150 aggregates, and the

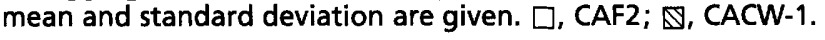

1 samples was digested by endo- $1,6-\beta$-glucanase. Thus the levels of 1,3- $\beta$ - and 1,6- $\beta$-glucan and mannan in cell walls of CACW-1 are equivalent to the parent CAF2. Stationary-phase cells were slightly more sensitive to Zymolyase $100 \mathrm{~T}$ lysis on several occasions of testing, but we are not confident that the slight increase $(5-10 \%$ in increased lysis rate) is significant (data not shown).

\section{Virulence studies on CACW-1}

The virulence of CACW-1 was slightly attenuated (Fig. 6) when compared to the isogenic parental strain CAF2 (experiment performed twice with similar results, and one set of data is depicted in Fig. 6). In addition, fewer c.f.u. were recovered from the kidneys of animals infected with CACW-1 compared to CAF2 (Table 4). It is difficult to predict what effect the slight decrease in generation time of CACW-1 (see above) might play in attenuating virulence, as compared to some alteration in the cell wall due to lack of the Bgl2p glucosyltransferase (see below). Regardless, the lack of Bgl2p glucosyltransferase reproducibly attenuated virulence in the standard mouse model. There was no significant difference in the aggregation state of CACW-1 compared to CAF2 when grown to stationary phase (Fig. 4, and see above) in the Sabouraud Dextrose Broth used to grow infecting inoculums. Thus it is unlikely that differences in aggregation caused the attenuation in virulence.

\section{MIC profiles}

The MIC values of several antifungal drugs, especially those acting by way of perturbation of cell wall synthesis or assembly, were measured on strains CAF2 and 
Table 3. Analysis of wall glucan

Walls prepared from exponential- and stationary-phase cells were digested with Zymolyase 100T and released material was fractionated on Sephadex G50.

\begin{tabular}{|lccc|}
\hline Strain & $\begin{array}{c}\text { Zymolyase- } \\
\text { released hexose } \\
\text { ( } \mu \text { g glucose } \\
\text { equivalents) }\end{array}$ & $\begin{array}{c}\text { Hexose in } \\
\text { peak 1 } \\
(\%) \dagger\end{array}$ & $\begin{array}{c}\text { Hexose in } \\
\text { peak 2 } \\
(\%) \neq\end{array}$ \\
\hline CAF2 exponential & $1116 \pm 120$ & $49 \cdot 1$ & $50 \cdot 9$ \\
CAF2 stationary & $1303 \pm 147$ & $43 \cdot 4$ & $56 \cdot 6$ \\
CACW-1 exponential & $1453 \pm 87$ & $45 \cdot 2$ & $54 \cdot 8$ \\
CACW-1 stationary & $1133 \pm 108$ & $48 \cdot 8$ & $51 \cdot 2$ \\
\hline
\end{tabular}

* Assayed in triplicate with mean and standard deviation given.

†Peak 1 (void volume) contained 1,6- $\beta$-glucan and mannan as assessed by gas chromatography of peracetylated alditol acetate derivatives and methylation analysis. Data are the mean of two measurements.

$\ddagger$ Peak 2 (included fraction) contained 1,3- $\beta$-oligosaccharides as assessed by methylation analysis. Data are the mean of two measurements.

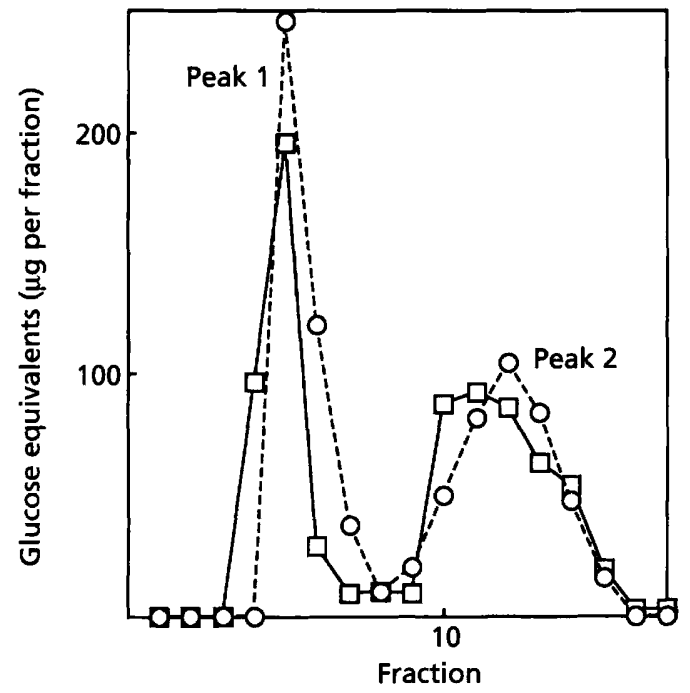

Fig. 5. Analysis of wall glucan and mannan by size exclusion chromatography. SDS-extracted walls from exponentially growing cells were digested with Zymolyase 100T and the released hexose was fractionated on Sephadex G50. Peak 1 (void volume) contained mannan and 1,6- $\beta$-glucan; peak 2 (included volume) contained $1,3-\beta$-oligosaccharides released by the 1,3- $\beta$-glucanases in Zymolyase 100T. $\square$, CAF2; O, CACW- 1 . Profiles for CAF2 and CACW-1 stationary-phase cells gave similar patterns (data not shown).

CACW-1 (Table 5). The most striking observations were: (1) the 30-250-fold increase in sensitivity of CACW-1 to the chitin synthase inhibitor nikkomycin Z compared to CAF 2 at 37 and $42^{\circ} \mathrm{C}$; and (2) the increased sensitivity of both CAF2 and CACW-1 to nikkomycin Z when compared over the incubation temperatures 30,37 and $42{ }^{\circ} \mathrm{C}$. CACW-1 also showed a slight increase in sensitivity to Calcofluor white, which perturbs cell wall synthesis and assembly. In contrast, no significant
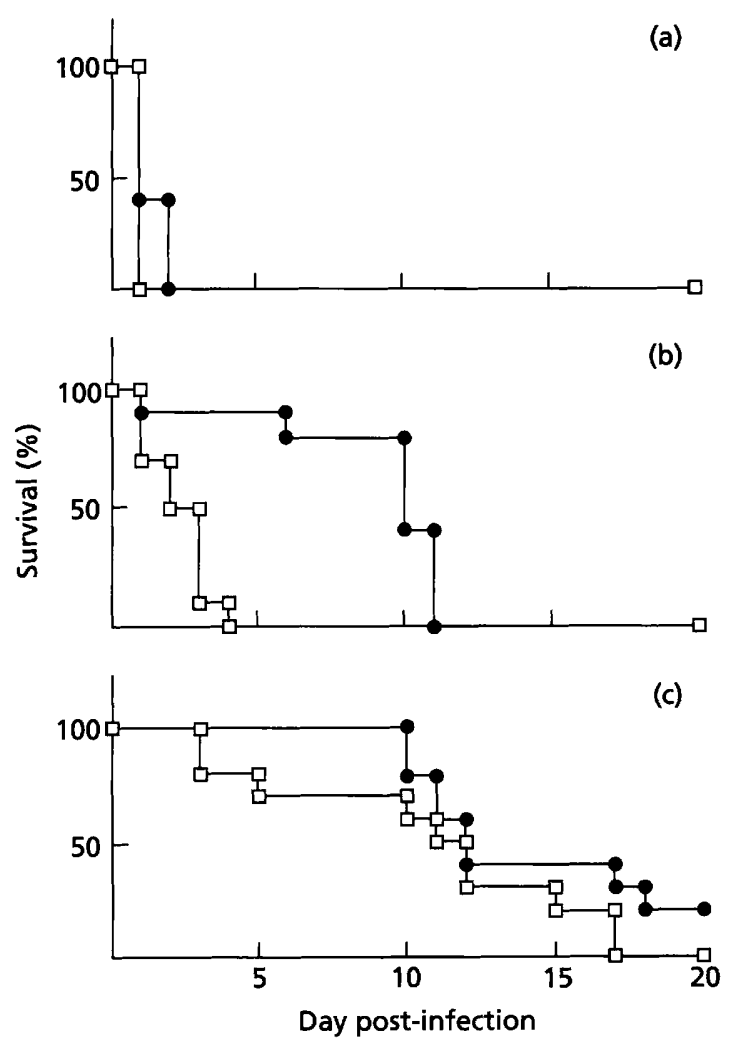

Fig. 6. Virulence of CAF2 ( $\square$ ) and CACW-1 (O) in the mouse model. Mice (10 for each group) were inoculated with (a) $1 \times 10^{7}$, (b) $1 \times 10^{6}$ or (c) $1 \times 10^{5}$ c.f.u. of each strain via the tail vein, and the time of death was recorded. Mean survival times (d) are: (a) 1.0 (CAF2) and 1.4 (CACW-1); (b) 2.3 (CAF2) and 9.1 (CACW-1); (c) 10.5 (CAF2) and 12.6 (CACW-1).

differences were observed in the MIC values for cilofungin and fusacandin A (inhibitors of glucan synthesis), staurosporine (inhibitor of wall synthesis via protein 
Table 4. Colonization of mouse kidney tissue following intravenous inoculation

Twenty female CF-1 mice were inoculated with C. albicans strains, and at days 1 and 4 kidney homogenates from 10 mice from each group were plated on Sabouraud Dextrose Agar. C. albicans colony counts were determined after $24 \mathrm{~h}$ incubation.

\begin{tabular}{|lccc|}
\hline Strain & $\begin{array}{c}\text { Inoculum } \\
\text { dose } \\
\text { (c.f.u.) }\end{array}$ & \multicolumn{2}{c|}{$\begin{array}{c}\text { c.f.u. recovered from } \\
\text { kidneys/c.f.u. inoculated }\end{array}$} \\
\cline { 2 - 4 } & & Day 1 & Day 4 \\
\hline CAF2 & $9.3 \times 10^{4}$ & $0.796( \pm 0.334)$ & $1.29( \pm 1 \cdot 183)$ \\
CACW-1 & $9.3 \times 10^{3}$ & $0.161( \pm 0.075)$ & $0.280( \pm 0.086)$ \\
& $5.0 \times 10^{4}$ & $0.070( \pm 0.026)$ & $0.032( \pm 0.008)$ \\
& $5.0 \times 10^{3}$ & $0.074( \pm 0.028)$ & $0.182( \pm 0.064)$ \\
\hline
\end{tabular}

* Mean values with standard deviation in parentheses.

Table 5. Effect of antifungal agents on CAF2 and CACW-1 strains at 30,37 and $42{ }^{\circ} \mathrm{C}$

MIC values were determined by micro broth dilution in SD medium plus $0.5 \%$ glucose at the indicated incubation temperatures, and results were scored on days 1,2 and 4. Values in parentheses are the fold difference in MIC between CAF2 and CACW-1 under the given conditions.

\begin{tabular}{|c|c|c|c|c|}
\hline \multirow{2}{*}{$\begin{array}{l}\text { Compound and } \\
\text { temperature }\end{array}$} & \multicolumn{2}{|c|}{ MIC day $1\left(\mu \mathrm{g} \mathrm{ml}^{-1}\right)$} & \multicolumn{2}{|c|}{ MIC day $2\left(\mu \mathrm{g} \mathrm{ml}^{-1}\right)$} \\
\hline & CAF2 & CACW-1 & CAF2 & CACW-1 \\
\hline \multicolumn{5}{|l|}{$30^{\circ} \mathrm{C}$} \\
\hline Fusacandin A & $1 \cdot 95$ & $3 \cdot 9$ & $3 \cdot 9$ & $7 \cdot 8$ \\
\hline Cilofungin & 1.95 & 1.95 & 1.95 & 1.95 \\
\hline Calcofluor white & $15 \cdot 6$ & 3.9 & $15 \cdot 6$ & $7 \cdot 8$ \\
\hline Staurosporine & $0 \cdot 98$ & 0.5 & $15 \cdot 6$ & $7 \cdot 8$ \\
\hline Amphotericin B & $0 \cdot 5$ & 0.5 & 0.5 & 0.5 \\
\hline Tunicamycin & $15 \cdot 6$ & $15 \cdot 6$ & $15 \cdot 6$ & $31 \cdot 25$ \\
\hline Nikkomycin Z & $>250$ & $>250$ & $>250$ & $>250$ \\
\hline Miconazole & $7 \cdot 8$ & $7 \cdot 8$ & $15 \cdot 6$ & $15 \cdot 6$ \\
\hline \multicolumn{5}{|l|}{$37^{\circ} \mathrm{C}$} \\
\hline Fusacandin A & $0 \cdot 98$ & $1 \cdot 95$ & $7 \cdot 8$ & $7 \cdot 8$ \\
\hline Cilofungin & 1.95 & 1.95 & 3.9 & $3 \cdot 9$ \\
\hline Calcofluor white & $3 \cdot 9$ & $0.98(4)$ & $15 \cdot 6$ & $1.95(8)$ \\
\hline Staurosporine & $<0.03$ & $<0.03$ & 0.98 & 1.95 \\
\hline Amphotericin B & $0 \cdot 24$ & 0.24 & 0.98 & 0.98 \\
\hline Tunicamycin & $7 \cdot 8$ & $15 \cdot 6$ & $31 \cdot 25$ & $15 \cdot 6$ \\
\hline Nikkomycin Z & 250 & $0.98(255)$ & 250 & $7 \cdot 8(32)$ \\
\hline Miconazole & 0.5 & 0.5 & $0 \cdot 5$ & 0.98 \\
\hline \multirow{2}{*}{$\begin{array}{l}\text { Compound and } \\
\text { temperature }\end{array}$} & \multicolumn{2}{|c|}{ MIC day $2\left(\mu \mathrm{g} \mathrm{ml}^{-1}\right)$} & \multicolumn{2}{|c|}{ MIC day $4\left(\mu \mathrm{g} \mathrm{ml}^{-1}\right)$} \\
\hline & CAF2 & CACW-1 & CAF2 & CACW-1 \\
\hline \multicolumn{5}{|l|}{$42^{\circ} \mathrm{C}$} \\
\hline Fusacandin A & $7 \cdot 8$ & 1.95 & $7 \cdot 8$ & 3.9 \\
\hline Cilofungin & 1.95 & 0.98 & $3 \cdot 9$ & 1.95 \\
\hline Calcofluor white & 1.95 & 0.98 & $7 \cdot 8$ & $0.98(8)$ \\
\hline Staurosporine & $0 \cdot 5$ & 0.5 & 0.98 & 0.98 \\
\hline Amphotericin B & $0 \cdot 24$ & $0 \cdot 24$ & $0 \cdot 5$ & 0.98 \\
\hline Tunicamycin & $7 \cdot 8$ & $3 \cdot 9$ & $15 \cdot 6$ & $15 \cdot 6$ \\
\hline Nikkomycin Z & $15 \cdot 6$ & $0.5(31)$ & 125 & $1.95(64)$ \\
\hline Miconazole & 1.98 & 0.5 & 1.98 & 0.98 \\
\hline
\end{tabular}


kinase C), amphotericin B (binding to ergosterol), tunicamycin (inhibitor of glycoprotein assembly) or miconazole (inhibitor of ergosterol synthesis).

Nikkomycin $Z$ affected cell morphology even at subMIC levels. CAF2 cells appeared as pseudo-hyphal or hyphal forms in the presence of sub-MIC levels of nikkomycin $\mathrm{Z}$ at all three temperatures. This morphology may be related to partial inhibition of one of the three known chitin synthases. The sensitivity to nikkomycin $\mathrm{Z}$ does vary between the three forms of chitin synthase in S. cerevisiae (Gaughran et al., 1994). CAF2 demonstrated approximately $72 \%$ pseudo-hyphal or hyphal forms after $24 \mathrm{~h}$ growth with the sub-MIC dose of $62.5 \mu \mathrm{g}$ nikkomycin $\mathrm{Z} \mathrm{ml}^{-1}$ at $37^{\circ} \mathrm{C}$. Untreated cells showed only about $12 \%$ hyphal growth, and the yeast form appeared as oblong, unicellular cells $(7.5 \mu \mathrm{m}$ long by $4 \mu \mathrm{m}$ wide) at $37^{\circ} \mathrm{C}$.

In contrast, the CACW-1 strain grown at $37^{\circ} \mathrm{C}$ had a different proportion of hyphal growth when treated with sub-MIC levels of nikkomycin Z. Approximately $70 \%$ of the cells were yeast forms $(10 \mu \mathrm{m}$ long by $7.5 \mu \mathrm{m}$ wide) whereas only $30 \%$ were hyphal or pseudo-hyphal when observed after $24 \mathrm{~h}$ treatment with a sub-MIC dose of $0.24 \mu \mathrm{g}$ nikkomycin $\mathrm{Z} \mathrm{ml}^{-1}$ at $37^{\circ} \mathrm{C}$. Extensive lysis of strain CACW-1 occurred at the MIC value of $7 \cdot 8 \mu \mathrm{g}$ nikkomycin $\mathrm{Z} \mathrm{ml}^{-1}$ at $37^{\circ} \mathrm{C}$ after $48 \mathrm{~h}$. Increasing the temperature to $42^{\circ} \mathrm{C}$ did not change the nikkomycin $\mathrm{Z}$ effects on the CAF2 or CACW-1 strains. However, a higher ratio of hyphal/pseudo-hyphal growth (20-30\%) was seen in both untreated strains at $42{ }^{\circ} \mathrm{C}$.

The dramatic increase in sensitivity to nikkomycin $\mathrm{Z}$ is of particular interest, and indicates that loss of $\mathrm{Bgl} 2 \mathrm{p}$ glucosyltransferase renders cells more dependent on chitin as a structural element in the wall. We have previously proposed repair functions for the $\mathrm{Bgl} 2 \mathrm{p}$ glucosyltransferase in that it catalyses a 'strand-rejoining' reaction using a free reducing and a free nonreducing 1,3- $\beta$-glucan strand (Goldman et al., 1995). Free ends would be generated not only by the action of endoglucanase activity, perhaps activated during bud emergence or cell septation/cell separation, but also following initiation and completion of new $1,3-\beta$-glucan strands. There is a well-known relationship between chitinase activity and chitin repair during cell septation and separation (Kuranda \& Robbins, 1991; Cabib et al., 1992). Loss of chitin repair (CHS1) function leads to lysis of separating cells due to chitinase action at the septum. Similar biochemical events probably balance glucan synthesis and hydrolysis during bud emergence and cell septation/separation. Thus it is feasible that some aspect of bud emergence and or septation/ separation is compromised in the Bgl2p-deficient CACW-1 strain (perhaps strand rejoining of glucan nicked by endoglucanase), rendering the cells more dependent on chitin when grown at 37 and $42{ }^{\circ} \mathrm{C}$.

In conclusion, we have described several phenotypic changes in a $C$. albicans strain lacking the Bgl $2 \mathrm{p}$ glucosyltransferase due to disruption of the two $B G L 2$ alleles. This strain lacks cell-wall-associated Bgl2p glucosyltransferase activity, but contains glucosyltransferase activity of an as yet unknown type. Changes indicating that cell wall alterations have occurred in strain CACW-1 include (1) extensive aggregation of CACW-1 stationary-phase cells, (2) increased sensitivity of CACW-1 to nikkomycin $Z$, and possibly (3) the attenuated virulence in the mouse infection model. The function of other non-BGL2-encoded glucosyltransferase activities in C. albicans and $S$. cerevisiae is currently being investigated.

\section{ACKNOWLEDGEMENTS}

We thank John Capobianco and Dorothy Zakula for running the Bglp2 transferase reactions, and W. Fonzi and P. Sullivan for kindly providing strains, plasmids and other reagents.

\section{REFERENCES}

Boeke, J. D., LaCroute, F. \& Fink, G. R. (1984). A positive selection for mutants lacking orotidine-5' -phosphate decarboxylase activity in yeast: 5-fluoro-orotic acid resistance. Mol Gen Genet 197, 345-346.

Bulawa, C. E., Miller, D. W., Henry, K. L. \& Becker, J. M. (1995). Attenuated virulence of chitin-deficient mutants of Candida albicans. Proc Natl Acad Sci USA 92, 10570-10574.

Burgers, P. M. J. \& Percival, K. J. (1987). Transformation of yeast spheroplasts without cell fusion. Anal Biochem 163, 393-397.

Cabib, E., Silverman, S. J. \& Shaw, J. A. (1992). Chitinase and chitin synthase 1 : counterbalancing activities in cell separation of Saccharomyces cerevisiae. J Gen Microbiol 138, 97-102.

Coen, M., Lerner, C. \& Goldman, R. C. (1994). Synthesis of yeast wall glucan and evidence for glucan metabolism in a Saccharomyces cerevisiae whole cell system. Microbiology 140, 2229-2237.

Dubois, M., Gilles, K. A., Hamilton, J. K., Rebers, P. A. \& Smith, F. (1956). Colorimetric method for determination of sugars and related substances. Anal Chem 28, 350-356.

Elorza, V., Mormeneo, S., Garcia de la Cruz, F., Gimeno, C. \& Sentandreu, R. (1989). Evidence for the formation of covalent bonds between macromolecules in the domain of the wall of Candida albicans mycelial cells. Biochem Biophys Res Commun 162, 1118-1125.

Fonzi, W. A. \& Irwin, M. Y. (1993). Isogenic strain construction and gene mapping in Candida albicans. Genetics 134, 717-728.

Gaughran, J. P., Lai, M. H., Kirsch, D. R. \& Silverman, S. J. (1994). Nikkomycin $\mathrm{Z}$ is a specific inhibitor of Saccharomyces cerevisiae chitin synthase isozyme Chs 3 in vitro and in vivo. J Bacteriol 176, 5857-5860.

Goldman, R. C., Sullivan, P. A., Zakula, D. \& Capobianco, J. O. (1995). Kinetics of $\beta-1,3$ glucan interaction at the donor and acceptor sites of the fungal glucosyltransferase encoded by the BGL2 gene. Eur J Biochem 227, 372-378.

Hartland, R. P., Emerson, G. W. \& Sullivan, P. A. (1991). A secreted $\beta$-glucan-branching enzyme from Candida albicans. Proc $R$ Soc Lond B Biol Sci 246, 155-160.

Hoffman, C. S. \& Winston, F. (1987). A ten-minute DNA preparation from yeast efficiently releases autonomous plasmids for transformation of Escherichia coli. Gene 57, 267-272.

Klebl, F. \& Tanner, W. (1989). Molecular cloning of a cell wall exo$\beta$-1,3-glucanase from Saccharomyces cerevisiae. J Bacteriol 171, $6259-6264$. 
Kollar, R., Petrokova, E., Ashwell, G., Robbins, P. W. \& Cabib, E. (1995). Architecture of the yeast cell wall. The linkage between chitin and $\beta(1,3)$-glucan. $J$ Biol Chem 270, 1170-1178.

Kuranda, M. J. \& Robbins, P. W. (1991). Chitinase is required for cell separation during growth of Saccharomyces cerevisiae. J Biol Chem 266, 19758-19767.

Maniatis, T., Fritsch, E. F. \& Sambrook, J. (1982). Molecular Cloning: a Laboratory Manual. Cold Spring Harbor, NY: Cold Spring Harbor Laboratory.

Mio, T., Yabe, T., Sudoh, M., Satoh, Y., Nakajima, T., Arisawa, M. \& Yamada-Okabe, H. (1996). Role of three chitin synthase genes in the growth of Candida albicans. J Bacteriol 178, 2416-2419.

Mrsa, V., Klebl, F. \& Tanner, W. (1993). Purification and characterization of the Saccharomyces cerevisiae BGL2 gene product, a cell wall endo- $\beta$-1,3-glucanase. $J$ Bacteriol 175, 2102-2106.

Reiss, E., Hearn, V. M., Poulain, D. \& Shepherd, M. G. (1992). Structure and function of the fungal cell wall. J Med Vet Mycol 30, 143-156.
Shepherd, M. G. (1987). Cell envelope of Candida albicans. Crit Rev Microbiol 15, 7-25.

Shepherd, M. G., Poulter, R. T. \& Sullivan, P. A. (1985). Candida albicans: biology, genetics, and pathogenicity. Annu Rev Microbiol 39, 579-614.

Sherman, F., Fink, G. R. \& Hicks, J. B. (1982). Methods in Yeast Genetics. Cold Spring Harbor, NY: Cold Spring Harbor Laboratory.

Sietsma, J. H. \& Wessels, J. G. H. (1981). Solubility of $(1 \rightarrow 3)-\beta$ $\mathrm{D} /(1 \rightarrow 6)$-D-glucan in fungal walls: importance of presumed linkage between glucan and chitin. J Gen Microbiol 125, 209-212.

Surarit, R., Gopal, P. K. \& Shepherd, M. G. (1988). Evidence for a glycosidic linkage between chitin and glucan in the cell wall of Candida albicans. J Gen Microbiol 134, 1723-1730.

Received 27 June 1996; revised 30 September 1996; accepted 1 October 1996. 